By Jeroen Sondervan ( $\underline{\mathrm{ORCID})}$

\title{
Interview: Adrian Martin Speaks Out in Favor of Open Access
}

In the coming period, I will interview a number of researchers about their work and to what extent open access has a role to play in it. The debate around open access is often held on a policy level, with university boards or libraries and publishers. But the voices of those that actually make use of research papers, books and research data are often not heard. How does a researcher or practitioner see the open access movement enabling free online access to scholarly works? How does this affect their work? What initiatives of interest are being developed in particular fields and what are personal experiences with open access publishing? All kinds of questions that hopefully lead to helpful answers for other researchers engaging with open access.

First interview is with Adrian Martin. Adrian was born in 1959 in Australia. He is a film and arts critic for more than 30 years and as an associate professor in Film Culture and Theory he is currently affiliated with Monash University. His work has appeared in many journals and newspapers around the world, and has been translated into over twenty languages.

\section{Jeroen Sondervan: When did you first hear of open access as a new way of distributing research to a wider audience?}

Adrian Martin: To appreciate my particular viewpoint on open access issues, you probably need to know where I am 'coming from'. I am not now, and have rarely been in my life so far, a salaried academic. I have spent most of my life as what I guess is called an 'independent researcher'. I have sometimes called myself a 'freelance intellectual', but I guess the more prosaic description would simply be 'freelance writer/speaker'. So, not a journalist in the strict sense (I have never worked fulltime for any newspaper or magazine), and only sometimes an employed academic within the university system.

Therefore, my entry into these issues is as someone who, at the end of the 1990s, began to get heavily involved in the publication of online magazines, whether as editor, writer, or translator. These were not commercial or industrial publications, they were 'labour of love' projects, kin to the world of 'small print magazines' in the Australian arts scene (which I had been a part of in the 1980s). No special subscription process was required; it was always, simply, a completely open and accessible website. My entrée to this new, global, online, scene was through Bill Mousoulis, the founder of Senses of Cinema and later I was part of the editorial teams of Rouge, and currently LOLA. And I have contributed to many Internet publications of this kind since the start of the $21^{\text {st }}$ century. The latter two publications do not use academic 'peer review' (although everything is carefully checked and edited), and are run on an active 'curation' model (i.e., we approach specific people to ask for texts) rather than an 'open submission' model.

I say this in order to make clear that my attitude and approach does not come from only, or even mainly, an academic/scholarly perspective. For me, open access is not primarily or solely about making formerly 'closed' academic research available to all - although that is certainly one important part of the field. Open access is about - well, open access, in the strongly political sense of making people feel that they are not excluded from reading, seeing, learning or experiencing anything that exists in the world. Long before I encountered the inspiring works of Jacques Rancière, I believe I 
agreed deeply with his political philosophy: that what we have to fight, at every moment, is the unequal 'distribution of the sensible', which means the ways in which a culture tries to enforce what is 'appropriate' for the citizens in each sector of society. As a kid who grew up in a working-class suburb of Australia before drifting off on the lines-of-flight offered by cinephilia and cultural writing, I am all too painfully aware of the types of learning and cultural experience that so many people deny themselves, because they have already internalised the sad conviction that it is 'not for them', not consistent with their 'place' in the world. Smash all such places, I say!

This is why I am temperamentally opposed to any tendency to keep the discussion of open access restricted to a discussion of university scholarship - or, indeed, as sometimes happens, with the effect of strengthening the 'professional' borders around this scholarship, and thus shutting non-university people (such as I consider myself today) out of the game. Let me give you a controversial example. I use, and encourage the use of Academia.edu. It is the only 'repository of scholarly knowledge' I know of that - despite its unwise name! - anyone can easily join and enjoy (once they are informed of it, and are encouraged to do so). Now, many people complain about the capitalistic nature of this site, and everything they say in this regard may be true. But when I ask them for an alternative that is as good and as extensive in its holdings, I am directed to 'professional' university repositories for texts from which I am necessarily excluded from the outset, since I do not have a university job. This is bad! And reinforces all the worst tendencies in the field.

Likewise, I bristle at the suggestion (it occasionally comes up) that an online publication such as LOLA (among many other examples) is not really 'scholarly'. Online magazines are regularly downgraded by being described as mere 'blogs' (when this is not so!), with no professional standards, etc. etc.. But my drive is, above all, a democratic one. I work mainly outside the university setting because I want access to be truly open. And I want the work to be lively and unalienated. A tall order, but we must forever strive for it! So, in a nutshell, for me the term 'open access' simply means 'material freely available to all online' - but material that is well written, well prepared, well edited and well presented.

\section{JS: Did you ever publish one of your papers (or other scholarly material) in open access?}

AM: Well, according to my above context of criteria, yes: a great deal, literally hundreds of essays! I believe I have covered a wide range of venues, from what I am calling Internet magazines (such as Transit and Desistfilm), through to online-only peer-reviewed publications (such as Movie, Necsus and The Cine-Files), through to the 'paywall' academic journals (such as Screen, Studies in Documentary Film and Continuum) which seem to exist less and less as solid, physical entities that one could actually obtain and hold a copy of (try buying one if you're not a library), and more and more as a bunch of detached, virtual items (each article its own little island) on a digital checkout page of a wealthy publishing house's website! This last point also applies to the chapters I have written for various academic books.

When I taught at Monash (Australia) and Goethe (Germany) universities from 2007 to 2015, I decided to 'take a detour' into this world of academic writing - partly because the institution demands or requires it, for the sake of judging promotions and so forth. I do not regret the type of in-depth, historical work, on a range of subjects, that this opportunity allowed me to do. But I am more than happy to be back in the less constrained, less rule-bound world of freelance writing. The university, finally, is all about a far too severe, restricted and vicious 'distribution of the sensible' - it tends to perpetuate itself, and close its professional ranks, rather than truly open its borders to what is beyond itself. 
One of my best and happiest experiences with open access has been with the small American publisher, punctum books. I did my little book Last Day Every Day with them, and it has had three editions in three different languages there. Their care and dedication to projects is outstanding. The politics of punctum as an enterprise are incredibly noble and radical: people can opt to pay something for their books, or download them for free if they wish. Likewise, authors can take any money that comes to them, or choose to plough it back into the company (that's what I did, and probably most of their authors do). At the same time, certain professional/academic standards are upheld: punctum has an extraordinary board, manuscripts are sent out for reporting, and so forth. They both 'play the game' of academic publishing as far as they have to, and also challenge the system in a remarkable way. I am proud to be involved with them.

JS: You are an Australian scholar, living in Spain, traveling for lectures and conferences and studying and writing about a global topic as film and media studies is. How does free online scholarly content affect your daily work as a scholar?

AM: Well, I enjoy an extraordinary amount of access to the work of other critics and scholars, especially through Academia.edu, and through postings of links by individuals on social media. At the same time, the 'paywalls' shut me out, because the purchase rates are too high for me as an individual, and I have no university-sanctioned reading/downloading access. As a freelance writer, I have to go where the work is, and where the money (very modest!) is. So that itinerary necessarily cuts across 'commercial' and 'academic' lines, and also involves me with many brave projects that are largely non-academic, and commercial only on an artisanal scale: literary projects such as Australia's Cordite, for example.

JS: In your first answer, you already addressed the issues of Academia.edu (and I guess you can extend this to other commercial products with similar functionalities like ResearchGate) but you also stress the need for a good place to share papers and research output. In the sciences, the preprint and postprint is an excepted and efficient standard in the scholarly communication process. Even publishers allow it. Lots of institutional archives (e.g. ArXiv, and SSRN) have seen the light mid-90s. And the use of those repositories increases every year. In the humanities, there is no such culture. Do you think this could change in a time where sharing initial ideas is becoming easier? Or is the writing and publishing culture in the humanities intrinsically different from that in the sciences?

AM: You offer a very intriguing comparative perspective here, Jeroen. I have no experience of scholarship in the sciences, so what you say is surprising (and good!) news to me. Perhaps, in the humanities, there has been, for too long a time, a certain anxious aura built up around the individual 'ownership' of one's ideas - and thereby most of us have gone along with this perceived need not to share our work so readily or easily in the preprint and postprint ways that you describe. But I do think this can change, and quite radically, if humanities people are encouraged to go in this direction. One can already see the signs of it, when scholars share their drafts of papers more readily (and widely) than before. I think it would be a very productive development.

JS: One of the biggest hurdles to take in the next 5 to 10 years regarding open access in the humanities are the costs of publishing. In the sciences, the dominant business model is based on APCs (Article Processing Charges). In the humanities this model is a problem. One of the reasons is that research budgets in the humanities and social sciences are much lower. Other reasons given are that since journal prices in the sciences are much higher there was an urgency to transfer to an open access environment. Subscription costs for humanities journals are much lower. 
The majority of open access journals in the humanities and also in media studies have another business model and are often subsidized by institutions or foundations. But subsidies are often temporary. New initiatives like Open Library of Humanities and Knowledge Unlatched come up with different financial models, all aimed at unburdening individual authors, but all of these models still need to prove themselves. Nevertheless, things are changing. How do you see a sustainable open access publishing environment for the humanities, and more specifically film and media studies?

AM: Issues of funding - and money, in general - are vexing indeed. Once again, let me make clear where I'm exactly 'coming from'. With Rouge and LOLA magazines, we have never received, or even sought, any government funding or any kind of arts-industry subsidy; we have never sought or accepted any advertising revenue; and we have never benefitted from any university grants of any kind. We run these magazines on virtually no money (beyond basic operating costs) and of course, as a result, we are unable to pay any contributor (and we are always upfront about that). This is perhaps an extreme, but not uncommon position. It was a decision that, in each case, we took. Why? Because we didn't want the restrictions, and obligations, that come with the 'public purse' - or, indeed, with almost any source of 'filthy lucre'! In Australia, for example, to accept government funding means you will have to meet a 'quota' of 'local/national content' - and if you don't, you won't get that subsidy again. Senses of Cinema has struggled with that poisoned chalice. With Rouge and LOLA, on the other hand, we enjoy the 'stateless' potentiality of online publishing - it is 'of the world' and belongs to the whole world (or at least, those in it who can read English!). Sometimes we engaged in (perhaps at our initiative) 'co-production' ventures, some of which panned out well (such as a book that Rouge made in collaboration with the Rotterdam Film Festival on Raúl Ruiz in 2004, or the publication last year in LOLA of certain chapters from a Japanese book tribute to Shigehiko Hasumi), and others which did not. But I and my colleagues stick to this generally penniless state of idealism!

I was naively shocked when I realised that academic publishers usually fund their open access projects through payments from writers! And that - as I discovered upon asking a few friends - some universities routinely subsidise these types of publications for their scholars. As a freelancer, once more, I am shut out from this particular system. Therefore, my next 'academic' book (Mysteries of Cinema for Amsterdam University Press) - ironically, largely comprised of my essays from nonacademic print publications! - will not be Open Access, because I cannot personally afford that, and I have no 'channel' of institutional funding that I can access. Once again, that's just the name of the game. I will be very happy when that book exists, but it will purely be a physical book for purchase only!

I have, therefore, no utopian visions for how to fund open access across the humanities board. Personally, I am currently looking into Patreon as a possible way to sustain arts/criticism-related website projects. It's a democratic model: people pay to support your ongoing work, to give you time and space to creatively do it. It's not like Kickstarter, which is geared to a single production, such as a feature film project. Patreon has proved a godsend for artists such as musicians. We shall see if it can also work in an open access publishing context.

JS: You are one of the founding fathers and practitioners of the so-called audiovisual essay, a new rising digital video format in academic publishing. Instead of writing a paper in words, a compilation of images offers a new textual structure. Another digital format is the enriched publication; articles or books with data included. One of the issues, besides arranging new forms of reviewing, is copyright and reuse. The audiovisual essay format obviously benefits from images with an open license, like the Creative Commons licenses. This makes it possible to reuse and remix these images. Archives are being digitized rapidly, but only a small portion is currently available in the public domain. Scholars 


\section{are often not allowed to make use of film quotes or stills in their works. How do you see the nearby future for using digitized media files for academic purposes in relation to copyright laws?}

AM: We are in an extraordinarily 'grey area' here - appropriately, I suppose, since things like LOLA are (I'm told) classified as 'grey Open Access'! And the legal situation for audiovisual works can vary greatly from nation to nation. We are in a historical moment when a lot of experimentation is going 'under the radar' of legal restriction, or (in the eyes of the big corporations) is considered simply too minor to consider taking any action against. Bear in mind that most critical/scholarly work in audiovisual essays (of the kind that I do in collaboration with my partner, Cristina Álvarez López) is not about making large sums of money; it is still a marginal, 'labour of love' activity, just as small, cultural magazines were in the 1980s.

This general fuzziness of the present moment is all to the good, in my opinion; we can all enjoy a certain freedom within it (with, occasionally, a 'bite' from above on particular questions of copyright: music use, for instance). I speak of no specific works or practitioners here, but much work in the audiovisual essay field happens both inside and outside of Creative Commons licenses. I don't think anyone should be restricted to using just that. The front on which we all have to battle is 'fair use' or 'fair dealing' (hence the disclaimer 'for study purposes only' that Cristina \& I place at the end of all our videos): the right to quote (and hence manipulate) audiovisual quotations for scholarly and artistic purposes, ranging all the way from lecture demonstration and re-montage analysis to parody and creative détournement/appropriation. The fully scholarly publication [in]Transition to which I and many others have contributed - no one will ever call that a blog! - takes full advantage, via its publishing 'home base' of USA, of everything that the fair use provisions in that country can allow. And I think you can see, if you peruse that site, how far the possibilities can go.

I very much liked the recent essay by Noah Berlatsky, "Fair Use Too Often Goes Unused" in The Chronicle of Higher Education, which argued that we - meaning not only writers and artists, but perhaps even more significantly editors and publishers - need to be questioning and pushing at the limits of the definition, practice and enforcement of fair use regulations. Too often (and I have experienced this myself) editors and publishers assume, at the outset, that a great deal is simply impossible, unthinkable: even the use of screenshots from movies! There is so much unnecessary fear and trepidation over such matters. Sure, no one wants to take a stupid risk and be sued as a result. But, to cite Berlatsky's conclusion:

"Books and journal articles about visual culture need to be able to engage with, analyse, and share visual culture. Fair use makes that possible - but only if authors and presses are willing to assert their rights. Presses may take on a small risk in asserting fair use. But in return they give readers an invaluable opportunity to see [and I would add: hear!] what scholars are talking about."

\section{JS: I want to thank you for this interview.}

(C) Adrian Martin \& Jeroen Sondervan, June 2017

This interview is published under a CC-BY 4.0 license. 